\title{
Iridium-Catalyzed Asymmetric Hydrogenation of Pyrrolo[1,2-a]pyrazinium Salts
}

\author{
Wen-Xue Huang, ${ }^{\dagger}$ Chang-Bin Yu, ${ }^{\dagger}$ Lei Shi, ${ }^{\dagger}$ and Yong-Gui Zhou ${ }^{*}, \dagger$ \\ ${ }^{\dagger}$ State Key Laboratory of Catalysis, Dalian Institute of Chemical Physics, Chinese Academy of Sciences, 457 Zhongshan Road, Dalian \\ 116023, China \\ ${ }^{\ddagger}$ State Key Laboratory of Organometallic Chemistry, Shanghai Institute of Organic Chemistry, Chinese Academy of Sciences, 345 \\ Lingling Lu, Shanghai 200032, China
}

\section{Supporting Information}

ABSTRACT: Highly enantioselective iridium-catalyzed hydrogenation of pyrrolo[1,2-a]pyrazinium salts has been achieved, providing a direct access to chiral 1,2,3,4-tetrahydropyrrolo[1,2a]pyrazine derivatives with up to $95 \%$ ee. The key feature of the reaction is the addition of cesium carbonate, which increases the conversion and prohibits the racemization pathway of products.

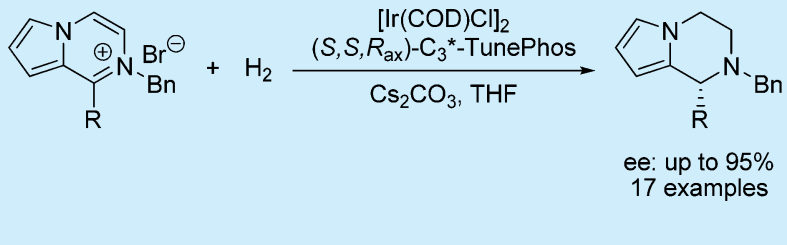

used. Only a few reports have been published, starting from partially saturated 3,4-dihydropyrrolo[1,2-a] pyrazines. $^{6}$

During the past decades, asymmetric hydrogenation of aromatic and heteroaromatic compounds has emerged as a powerful strategy for the synthesis of saturated or partially saturated cyclic molecules. ${ }^{7}$ Many aromatic substrates such as quinolines, ${ }^{8}$ isoquinolines, ${ }^{9}$ quinoxalines, ${ }^{10}$ pyridines, ${ }^{11}$ indoles, ${ }^{12}$ pyrroles, ${ }^{13}$ furans, ${ }^{14}$ imidazoles, ${ }^{15}$ thiophenes, ${ }^{16}$ and carbocyclic aromatic rings ${ }^{17}$ have been successfully hydrogenated with excellent enantioselectivities. The finding of a robust catalyst and proper activation of inactive aromatic compounds are key points for the successful implementation of the reaction. Substrate activation is a quite efficient and generally used strategy. With proper activators, such as Brønsted acids, ${ }^{18}$ chloroformates, ${ }^{9 a}$ or benzyl bromides, ${ }^{9 c, 11 f}$ the aromaticity of substrates can be partially destroyed, which facilitates hydrogenation.

Pyrrolo[1,2-a]pyrazines are bicyclic aromatics with one nitrogen atom in the bridgehead position of the fused pyrazine and pyrrole rings. Similar to pyridine and isoquinoline, both the substrate and the hydrogenated product possess a strong coordination ability. Once partially hydrogenated, the reserved pyrrole ring is relatively sensitive to acid, which further increases the difficulty in selective reduction of these substrates.

We envisaged that the activation of pyrrolo[1,2-a]pyrazine with benzyl bromide would efficiently reduce the coordination ability of the substrate and improve the reactivity for hydrogenation (Scheme 1). Herein, we disclose an iridiumcatalyzed asymmetric hydrogenation of pyrrolo[1,2-a]pyrazinium salts, providing the chiral 1,2,3,4-tetrahydropyrrolo$[1,2-a]$ pyrazines with up to $95 \%$ ee.

We began our studies with 2-benzyl-1-phenylpyrrolo[1,2a]pyrazin-2-ium bromide $2 \mathrm{a}$ as the model substrate using

Received: May 9, 2014

Published: June 9, 2014 
Scheme 1. Synthesis of Chiral 1,2,3,4-

Tetrahydropyrrolo $[1,2-a]$ pyrazine via Asymmetric Hydrogenation

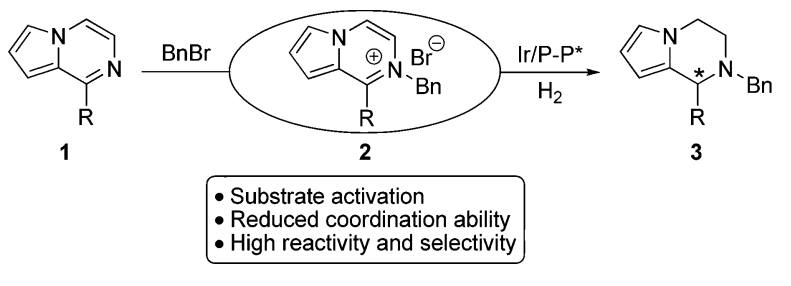

$[\operatorname{Ir}(\mathrm{COD}) \mathrm{Cl}]_{2} /\left(S, S, R_{\mathrm{ax}}\right)-\mathrm{C}_{3}{ }^{*}$-TunePhos as the catalyst (Table $1)$. Initial exploration of reaction conditions revealed the

Table 1. Optimization of the Reaction Conditions ${ }^{a}$

\begin{tabular}{|c|c|c|c|c|c|}
\hline & $\mathrm{V}_{\mathrm{Bn}}{ }^{\ominus}$ & $\begin{array}{c}\mathrm{H}_{2} \\
(600 \mathrm{psi})\end{array}$ & $\frac{[\operatorname{lr}(\mathrm{COD}) \mathrm{Cl}]_{2}}{\text { base, solvent, }}$ & & ${ }_{\mathrm{Ph}}^{*}{ }^{\mathrm{N}}{ }_{\mathrm{Bn}}$ \\
\hline entry & solvent & ligand & base (equiv) & $\operatorname{conv}(\%)^{b}$ & ee $(\%)^{c}$ \\
\hline 1 & $\mathrm{CH}_{2} \mathrm{Cl}_{2}$ & L1 & - & 28 & 8 \\
\hline 2 & toluene & L1 & - & 14 & 58 \\
\hline 3 & THF & L1 & - & 40 & 64 \\
\hline 4 & EtOAc & L1 & - & 26 & 55 \\
\hline 5 & THF & L1 & TEA (0.8) & $>95$ & 3 \\
\hline 6 & THF & L1 & $\mathrm{NaOH}(0.8)$ & $>95$ & 52 \\
\hline 7 & THF & L1 & $\mathrm{NaHCO}_{3}(0.8)$ & $>95$ & 76 \\
\hline 8 & THF & L1 & $\mathrm{Na}_{2} \mathrm{CO}_{3}(0.4)$ & $>95$ & 76 \\
\hline 9 & THF & L1 & $\mathrm{K}_{2} \mathrm{CO}_{3}(0.4)$ & $>95$ & 85 \\
\hline 10 & THF & L1 & $\mathrm{Cs}_{2} \mathrm{CO}_{3}(0.4)$ & $>95$ & 87 \\
\hline 11 & THF & L1 & $\mathrm{Cs}_{2} \mathrm{CO}_{3}(0.5)$ & $>95$ & 88 \\
\hline 12 & THF & L1 & $\mathrm{Cs}_{2} \mathrm{CO}_{3}(0.6)$ & $>95$ & 90 \\
\hline 13 & THF & $\mathbf{L} 2$ & $\mathrm{Cs}_{2} \mathrm{CO}_{3}(0.6)$ & $>95$ & 87 \\
\hline 14 & THF & L3 & $\mathrm{Cs}_{2} \mathrm{CO}_{3}(0.6)$ & $>95$ & 86 \\
\hline 15 & THF & L4 & $\mathrm{Cs}_{2} \mathrm{CO}_{3}(0.6)$ & $>95$ & 79 \\
\hline $16^{d}$ & THF & L1 & $\mathrm{Cs}_{2} \mathrm{CO}_{3}(0.6)$ & $>95$ & 92 \\
\hline
\end{tabular}

${ }^{a}$ Conditions: 2a $(0.20 \mathrm{mmol}),[\operatorname{Ir}(\mathrm{COD}) \mathrm{Cl}]_{2}(1.5 \mathrm{~mol} \%),\left(S, S, R_{\mathrm{ax}}\right)$ $\mathrm{C}_{3}{ }^{*}$-TunePhos (3.3 mol \%), $\mathrm{H}_{2}(600 \mathrm{psi})$, solvent $(3.0 \mathrm{~mL}), 2{ }^{\circ} \mathrm{C}, 24$ h; TEA $=$ triethylamine. ${ }^{b}$ Determined by ${ }^{1} \mathrm{H}$ NMR. ${ }^{c}$ Determined by HPLC with chiral column. ${ }^{d} \mathrm{H}_{2}$ (400 psi).

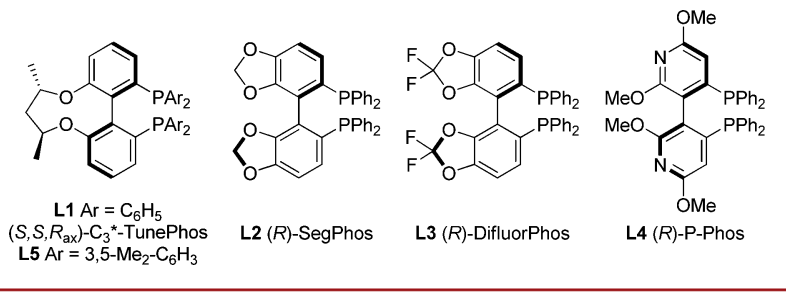

importance of the solvent. THF gave a much higher yield than other solvents, but only moderate enantioselectivity was obtained (entries 1-4).

Considering the structural similarity of pyrrolo[1,2-a]pyrazine with isoquinoline, we proposed the following reaction pathway based on our previous work. ${ }^{9 \mathrm{c}}$ As shown in Scheme 2, the substrates first undergo a 1,2-hydride addition to give a 1,2dihydropyrrolo[1,2-a]pyrazine intermediate $\mathbf{A}$, which would isomerize to an iminium salt $\mathbf{B}$ in the presence of in situ generated $\mathrm{HBr}$. Subsequent hydrogenation of the iminium salt gives the product. The in situ generated $\mathrm{HBr}$ is important for the reaction to proceed forward.
Scheme 2. A Proposed Hydrogenation Mechanism and the Racemization Pathway of $3 a$ under the Acidic Condition

Hydrogenation Pathway:

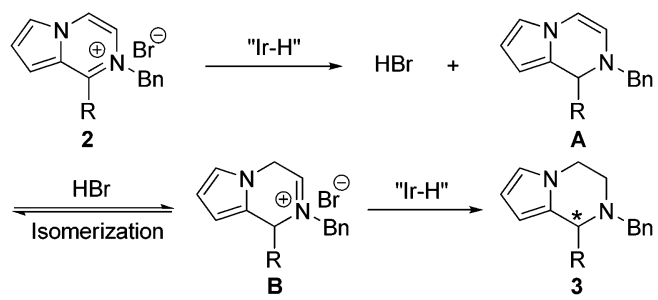

Racemization Pathway Under the Acidic Condition:

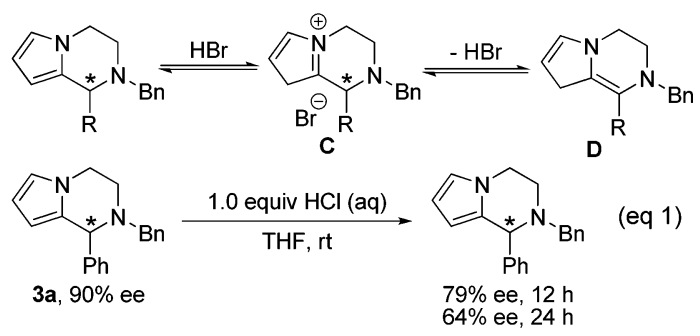

According to literature reports, molecules with a similar structure to $3 a$ are easy to racemize on silica gel. ${ }^{4 a}$ We speculated that the low ee value was caused by the partial racemization of $3 \mathbf{a}$ under the acidic conditions through enamine/iminium isomerization (Scheme 2 ). To verify this assumption, the product 3a was mixed with 1.0 equiv of $\mathrm{HCl}$ (aq) and stirred at room temperature (eq 1 in Scheme 2). The ee of 3a dropped from $90 \%$ to $79 \%$ in $12 \mathrm{~h}$. Upon further stirring, the ee dropped to $64 \%$. Based on these results, we decided to neutralize part of the $\mathrm{HBr}$ to prevent the substantial racemization of the product. To our surprise, upon adding 0.8 equiv of triethylamine (TEA), full conversion was realized, but the ee value was quite low (entry 5). ${ }^{19}$ This was possibly due to the coordination of the organic base to the catalyst. When the inorganic base was added, the reaction proceeded well with increased enantioselectivity. A screen of several kinds of inorganic bases showed that $\mathrm{Cs}_{2} \mathrm{CO}_{3}$ was the best choice, giving full conversion with $87 \%$ ee (entries 6-10).

To our delight, when excess $\mathrm{Cs}_{2} \mathrm{CO}_{3}$ was added to the reaction system, better enantioselectivities were obtained with no detection of the 1,2-dihydropyrrolo[1,2-a]pyrazine intermediate (entries 11-12). Because of the relatively poor solubility of $\mathrm{Cs}_{2} \mathrm{CO}_{3}$ in $\mathrm{THF}$, the neutralization rate may be slower than the rate of $\mathrm{HBr}$ generated. So the reaction proceeded well in the presence of excess $\mathrm{Cs}_{2} \mathrm{CO}_{3}$. Other commercially available chiral diphosphine ligands were also tested under the same conditions, but no ligand gave a better result than the initially used $\left(S, S, R_{\mathrm{ax}}\right)-\mathrm{C}_{3}{ }^{*}$-TunePhos (entries 13-15). A decrease of the hydrogen pressure had a positive effect on enantioselectivity (92\% ee, entry 16). Thus, the optimized conditions were established as $[\operatorname{Ir}(\mathrm{COD}) \mathrm{Cl}]_{2} /$ $\left(S, S, R_{\mathrm{ax}}\right)-\mathrm{C}_{3} *$-TunePhos $/ \mathrm{Cs}_{2} \mathrm{CO}_{3} / \mathrm{THF}$.

With the optimized reaction conditions in hand, the scope of iridium-catalyzed asymmetric hydrogenation of pyrrolo[1,2a]pyrazinium salts was explored (Table 2). In general, the transformations performed well with moderate to excellent yields under the standard conditions. The position and electronic effect of substituents on the phenyl ring had a great influence on the enantioselectivity. Substrates bearing eletron-donating groups on the 3-position gave much higher ee 
Table 2. Scope of the Asymmetric Hydrogenation of Pyrrolo[1,2-a] pyrazinium Salts $^{a}$

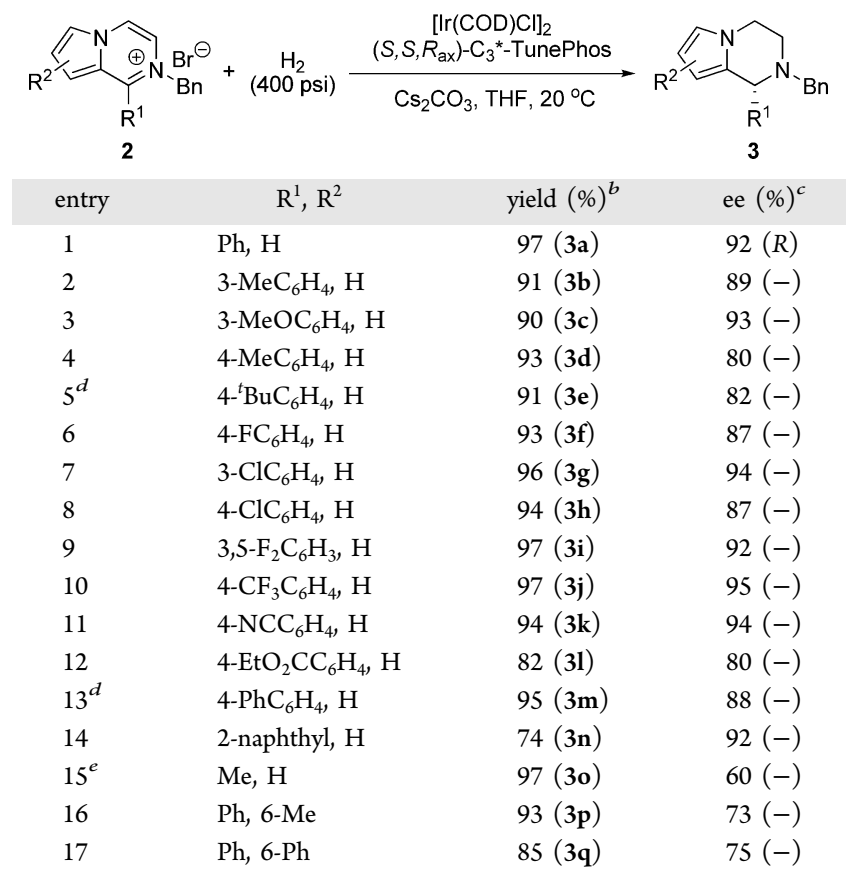

${ }^{a}$ Conditions: $2(0.20 \mathrm{mmol}),[\operatorname{Ir}(\mathrm{COD}) \mathrm{Cl}]_{2}(1.5 \mathrm{~mol} \%),\left(S, S, R_{a x}\right)$ $\mathrm{C}_{3}$ *-TunePhos (3.3 mol \%), $\mathrm{Cs}_{2} \mathrm{CO}_{3}(0.12 \mathrm{mmol}), \mathrm{H}_{2}$ (400 psi), THF $(3.0 \mathrm{~mL}), 20{ }^{\circ} \mathrm{C}, 24 \mathrm{~h} .{ }^{b}$ Isolated yield. ${ }^{c}$ Determined by HPLC. ${ }^{d} \mathrm{Cs}_{2} \mathrm{CO}_{3}(0.10 \mathrm{mmol})$ was used, $36 \mathrm{~h} .{ }^{e} \mathbf{L 5}$ was used as the ligand.

values than those on the 4-position (entries 2-5). However, for electron-withdrawing groups, generally high ee values were obtained (entries 6-10). Notably, a substrate with a $4-\mathrm{CF}_{3}$ group gave the best enantioselectivity ( $95 \%$ ee, entry 10$)$. The reaction system was also compatible with a cyano group and gave excellent ee ( $94 \%$ ee; entry 11 ), but for the ester group, a lower $80 \%$ ee was obtained (entry 12). For the biphenyl and naphthyl substituted substrates, good enantioselectivities were maintained (entries 13-14). 1-Methyl-pyrrolo[1,2-a]pyrazine was a suitable reaction partner, but only moderate enantioselectivity was obtained (60\% ee, entry 15$)$. Substrates with substituents on the pyrrole ring were also tested, providing the corresponding products with good yields and moderate ee values (entries 16-17).

After a single recrystallization from dichloromethane and $n$ hexane, the product 3 a could be obtained in $81 \%$ yield with up to $>99 \%$ ee. The absolute configuration of product $3 a$ was determined to be $R$ based on single-crystal X-ray diffraction analysis (Figure 2). ${ }^{20}$

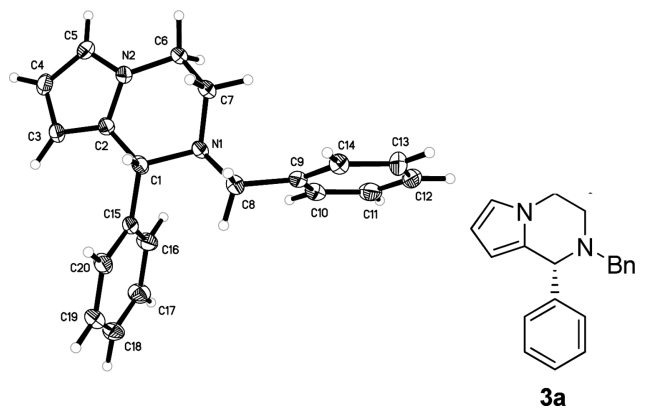

Figure 2. X-ray crystal structure of compound 3a.
Finally, to demonstrate the practicality of our approach, we directed our efforts to the removal of the benzyl group (Scheme 3 ). When 3a was subjected to 150 psi of $\mathrm{H}_{2}$ in the presence of

Scheme 3. Removal of the Benzyl Group

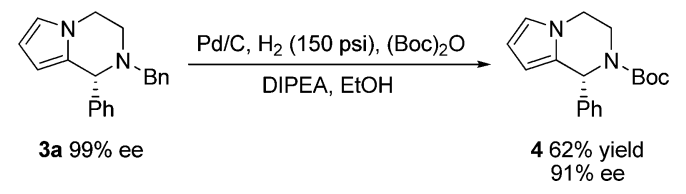

$5 \% \mathrm{Pd} / \mathrm{C},(\mathrm{Boc})_{2} \mathrm{O}$, and DIPEA in ethanol for 2 days, the desired product 4 was obtained in $62 \%$ yield with a slight drop of the ee value. The main side product arose from the opening of the piperazine ring (see the Supporting Information).

In conclusion, we have successfully realized the asymmetric hydrogenation of pyrrolo[1,2-a]pyrazinium salts with an iridium catalyst. This method provides a direct access to chiral 1,2,3,4-tetrahydropyrrolo[1,2-a]pyrazine derivatives with high to excellent ee values. The key feature of the reaction is the addition of cesium carbonate, which increases the conversion and prohibits the racemization pathway of products. Further efforts to illuminate the mechanism and apply this strategy to other challenging heteroaromatic compounds are ongoing in our laboratory.

\section{ASSOCIATED CONTENT}

\section{Supporting Information}

Experimental procedures, characterization data, X-ray structures, data for the determination of enantiomeric excess, and NMR spectra. This material is available free of charge via the Internet at http://pubs.acs.org.

\section{AUTHOR INFORMATION}

\section{Corresponding Author}

*E-mail: ygzhou@dicp.ac.cn.

Notes

The authors declare no competing financial interest.

\section{ACKNOWLEDGMENTS}

We are grateful for the financial support from the National Natural Science Foundation of China (21125208 and 21032003) and the National Basic Research Program of China (2010CB833300).

\section{REFERENCES}

(1) (a) Peresada, V. P.; Medvedev, O. S.; Likhosherstov, A. M.; Skoldinov, A. P. Khim.-Farm. Zh. 1987, 21, 1054. (b) Likhosherstov, A. M.; Filippova, O. V.; Peresada, V. P.; Kryzhanovskii, S. A.; Vititnova, M. B.; Kaverina, N. V.; Reznikov, K. M. Pharm. Chem. J. 2003, 37, 6. (c) Seredenin, S. B.; Voronina, T. A.; Beshimov, A.; Peresada, V. P.; Likhosherstov, A. M. RU 2099055, 1997. (d) Seredenin, S. B.; Voronina, T. A.; Likhosherstov, A. M.; Peresada, V. P.; Molodavkin, G. M.; Halikas, J. A. US 5378846, 1995, 10 pp. (e) Negoro, T.; Murata, M.; Ueda, S.; Fujitani, B.; Ono, Y.; Kuromiya, A.; Komiya, M.; Suzuki, K.; Matsumoto, J.-i. J. Med. Chem. 1998, 41, 4118.

(2) (a) Papeo, G.; Gómez-ZuritaFrau, M. A.; Borghi, D.; Varasi, M. Tetrahedron Lett. 2005, 46, 8635. (b) Al-Mourabit, A.; Zancanella, M. A.; Tilvic, S.; Romo, D. Nat. Prod. Rep. 2011, 28, 1229.

(3) Zhu, B.; Marinelli, B. A.; Goldschmidt, R.; Foleno, B. D.; Hilliard, J. J.; Bush, K.; Macielag, M. Bioorg. Med. Chem. Lett. 2009, 19, 4933.

(4) (a) Gualandi, A.; Cerisoli, L.; Monari, M.; Savoia, D. Synthesis 2011, 909. (b) Bhowmik, S.; Kumar, A. K. S.; Batra, S. Tetrahedron 
Lett. 2013, 54, 2251. (c) Li, G.; Rowland, G. B.; Rowland, E. B.; Antilla, J. C. Org. Lett. 2007, 9, 4065.

(5) He, Y.; Lin, M.; Li, Z.; Liang, X.; Li, G.; Antilla, J. C. Org. Lett. 2011, 13, 4490.

(6) For the hydrogenation of 3,4-dihydropyrrolo[1,2-a]pyrazines, see: (a) Skoldinov, A. P.; Likhosherstov, A. M.; Peresada, V. P. DE 2832488, 1980. (b) Skoldinov, A. P.; Likhosherstov, A. M.; Peresada, V. P. GB 2025936, 1980. (c) Skoldinov, A. P.; Likhosherstov, A. M.; Peresada, V. P. SU 798104, 1981. (d) Markus, H.; Tanja, W.; Sibylle, M.; Jens, N.; Andreas, G.; Valerjans, K.; Ronalds, Z.; Elina, E.; WO 2009095254, 2009.

(7) For reviews on hydrogenation of aromatics, see: (a) Wang, D.-S.; Chen, Q.-A.; Lu, S.-M.; Zhou, Y.-G. Chem. Rev. 2012, 112, 2557. (b) Fleury-Brégeot, N.; de La Fuente, V.; Castillón, S.; Claver, C. ChemCatChem 2010, 2, 1346. (c) Zhou, Y.-G. Acc. Chem. Res. 2007, 40, 1357. (d) Glorius, F. Org. Biomol. Chem. 2005, 3, 4171. (e) Lu, S.M.; Han, X.-W.; Zhou, Y.-G. Chin. J. Org. Chem. 2005, 25, 634. (f) Xie, J.-H.; Zhou, Q.-L. Acta Chim. Sinica 2012, 70, 1427.

(8) For selected works on asymmetric hydrogenation of quinolines, see: (a) Wang, W.-B.; Lu, S.-M.; Yang, P.-Y.; Han, X.-W.; Zhou, Y.-G. J. Am. Chem. Soc. 2003, 125, 10536. (b) Zhao, Y.-J.; Wang, Y.-Q.; Zhou, Y.-G. Chin. J. Catal. 2005, 26, 737. (c) Rueping, M.; Antonchick, A. P.; Theissmann, T. Angew. Chem., Int. Ed. 2006, 45, 3683. (d) Guo, Q.-S.; Du, D.-M.; Xu, J. Angew. Chem., Int. Ed. 2008, 47, 759. (e) Zhou, H.; Li, Z.; Wang, Z.; Wang, T.; Xu, L.; He, Y.; Fan, Q.-H.; Pan, J.; Gu, L.; Chan, A. S. C. Angew. Chem., Int. Ed. 2008, 47, 8464. (f) Wang, C.; Li, C.; Wu, X.; Pettman, A.; Xiao, J. Angew. Chem., Int. Ed. 2009, 48, 6524. (g) Wang, D.-W.; Wang, D.-S.; Chen, Q.-A.; Zhou, Y.-G. Chem.-Eur. J. 2010, 16, 1133. (h) Wang, T.; Zhuo, L.-G.; Li, Z.; Chen, F.; Ding, Z.; He, Y.; Fan, Q.-H.; Xiang, J.; Yu, Z.-X.; Chan, A. S. C. J. Am. Chem. Soc. 2011, 133, 9878. (i) Chen, Q.-A.; Gao, K.; Duan, Y.; Ye, Z.-S.; Shi, L.; Yang, Y.; Zhou, Y.-G. J. Am. Chem. Soc. 2012, 134, 2442. (j) Tu, X.-F.; Gong, L.-Z. Angew. Chem., Int. Ed. 2012, 51, 11346. (k) Cai, X.-F.; Chen, M.-W.; Ye, Z.-S.; Guo, R.-N.; Shi, L.; Li, Y.-Q.; Zhou, Y.-G. Chem.-Asian J. 2013, 8, 1381.

(9) For selected works on asymmetric hydrogenation of isoquinolines, see: (a) Lu, S.-M.; Wang, Y.-Q.; Han, X.-W.; Zhou, Y.-G. Angew. Chem., Int. Ed. 2006, 45, 2260. (b) Shi, L.; Ye, Z.-S.; Cao, L.-L.; Guo, R.-N.; Hu, Y.; Zhou, Y.-G. Angew, Chem., Int. Ed. 2012, 51, 8286. (c) Ye, Z.-S.; Guo, R.-N.; Cai, X.-F.; Chen, M.-W.; Shi, L.; Zhou, Y.-G. Angew. Chem., Int. Ed. 2013, 52, 3685. (d) Iimuro, A.; Yamaji, K.; Kandula, S.; Nagano, T.; Kita, Y.; Mashima, K. Angew. Chem., Int. Ed. 2013, 52, 2046. (e) Guo, R.-N.; Cai, X.-F.; Shi, L.; Ye, Z.-S.; Chen, M.W.; Zhou, Y.-G. Chem. Commun. 2013, 49, 8537.

(10) For selected works on asymmetric hydrogenation of quinoxalines, see: (a) Bianchini, C.; Barbaro, P.; Scapacci, G.; Farnetti, E.; Graziani, M. Organometallics 1998, 17, 3308. (b) Tang, W.; Xu, L.; Fan, Q.-H.; Wang, J.; Fan, B.; Zhou, Z.; Lam, K.-H.; Chan, A. S. C. Angew. Chem., Int. Ed. 2009, 48, 9135. (c) Rueping, M.; Tato, F.; Schoepke, F. R. Chem.-Eur. J. 2010, 16, 2688. (d) Chen, Q.-A.; Wang, D.-S.; Zhou, Y.-G.; Duan, Y.; Fan, H.-J.; Yang, Y.; Zhang, Z. J. Am. Chem. Soc. 2011, 133, 6126. (e) Gartigny, D.; Berhal, F.; Nagano, T.; Phansavath, P.; Ayad, T.; Gênet, J.-P.; Ohshima, T.; Mashima, K.; Ratovelomanena-Vidal, V. J. Org. Chem. 2012, 77, 4544.

(11) For selected works on asymmetric hydrogenation of pyridines, see: (a) Glorius, F.; Spielkamp, N.; Holle, S.; Goddard, R.; Lehmann, C. W. Angew. Chem., Int. Ed. 2004, 43, 2850. (b) legault, C. Y.; Charette, A. B. J. Am. Chem. Soc. 2005, 127, 8966. (c) Rueping, M.; Antonchick, A. P. Angew. Chem., Int. Ed. 2007, 46, 4562. (d) Wang, X.B.; Zeng, W.; Zhou, Y.-G. Tetrahedron Lett. 2008, 49, 4922. (e) Tang, W.-J.; Tan, J.; Xu, L.-J.; Lam, K.-H.; Fan, Q.-H.; Chan, A. S. C. Adv. Synth. Catal. 2010, 352, 1055. (f) Ye, Z.-S.; Chen, M.-W.; Chen, Q.-A.; Shi, L.; Duan, Y.; Zhou, Y.-G. Angew. Chem., Int. Ed. 2012, 51, 10181.

(12) For selected works on asymmetric hydrogenation of indoles, see: (a) Kuwano, R.; Sato, K.; Kurokawa, T.; Karube, D.; Ito, Y. J. Am. Chem. Soc. 2000, 122, 7614. (b) Kuwano, R.; Kashiwabara, M. Org. Lett. 2006, 8, 2653. (c) Wang, D.-S.; Chen, Q.-A.; Li, W.; Yu, C.-B.; Zhou, Y.-G.; Zhang, X. J. Am. Chem. Soc. 2010, 132, 8909. (d) Duan, Y.; Chen, M.-W.; Ye, Z.-S.; Wang, D.-S.; Chen, Q.-A.; Zhou, Y.-G.
Chem.-Eur. J. 2011, 17, 7193. (e) Wang, D.-S.; Tang, J.; Zhou, Y.-G.; Chen, M.-W.; Yu, C.-B.; Duan, Y.; Jiang, G.-F. Chem. Sci. 2011, 2, 803. (f) Duan, Y.; Chen, M.-W.; Chen, Q.-A.; Yu, C.-B.; Zhou, Y.-G. Org. Biomol. Chem. 2012, 10, 1235.

(13) For works on asymmetric hydrogenation of pyrroles, see: (a) Kuwano, R.; Kashiwabara, M.; Ohsumi, M.; Kusano, H. J. Am. Chem. Soc. 2008, 130, 808. (b) Wang, D.-S.; Ye, Z.-S.; Chen, Q.-A.; Zhou, Y.-G.; Yu, C.-B.; Fan, H.-J.; Duan, Y. J. Am. Chem. Soc. 2011, 133, 8866.

(14) For selected works on asymmetric hydrogenation of furans, see: (a) Kaiser, S.; Smidt, S. P.; Pfaltz, A. Angew. Chem., Int. Ed. 2006, 45, 5194. (b) Ortega, N.; Urban, S.; Beiring, B.; Glorius, F. Angew. Chem., Int. Ed. 2012, 51, 1710. (c) Wysocki, J.; Ortega, N.; Glorius, F. Angew. Chem., Int. Ed. 2014, 53, DOI: 10.1002/anie.201310985.

(15) For selected work on asymmetric hydrogenation of imidazoles, see: Kuwano, R.; Kameyama, N.; Ikeda, R. J. Am. Chem. Soc. 2011, 133, 7312.

(16) For selected work on asymmetric hydrogenation of thiophenes, see: Urban, S.; Beiring, B.; Ortega, N.; Paul, D.; Glorius, F. J. Am. Chem. Soc. 2012, 134, 15241.

(17) For selected works on asymmetric hydrogenation of carbocyclic aromatic rings, see: (a) Urban, S.; Ortega, N.; Glorius, F. Angew. Chem., Int. Ed. 2011, 50, 3803. (b) Kuwano, R.; Morioka, R; Kashiwabara, M.; Kameyama, N. Angew. Chem., Int. Ed. 2012, 51, 4136. (c) Ye, Z.-S.; Shi, L.; Zhou, Y.-G. Synlett 2014, 25, 928.

(18) For a review, see: Yu, Z.; Jin, W.; Jiang, Q. Angew. Chem., Int. Ed. 2012, 51, 6060 .

(19) For a base to increase conversion in the hydrogenation of quinolinium salts, see: Dragan, V.; McWilliams, J. C.; Miller, R; Sutherland, K.; Dillon, J. L.; O’Brien, M. K. Org. Lett. 2013, 15, 2942.

(20) CCDC 962691 contains the supplementary crystallographic data for this paper. These can be obtained free of charge from The Cambridge Crystallographic Data Centre via www.ccdc.cam.ac.uk/ data_request/cif. 